I only get about in one building

I stay in one room

I stay in bed more

I stay in bed most of the time

I do not use public transport now

I do not go into the shopping centre.

I do not go out to visit people at all

I spend most of my time partly dressed or in pyjamas

I do not do any of the clothes washing I would usually do

My sexual activity is decreased.

Lest it should be thought that such items represent no more than "noise" in the background of the scoring system, it should be noted that those of the above list which feature on the mobility domain (one of 12 domains on the FLP) contribute $56 \%$ of that score. If respondents were followed up as outpatients an inappropriate impression of improvement could be gained simply because the respondent is no longer restricted by the requirements of the hospital.

Research designs which involve at least one hospital based completion of a health status measure are widely used. To avoid the danger of results being seriously confounded by setting fellow researchers should be alert to this problem and careful in their selection of questionnaires.

SUE ZIEBLAND RAY FITZPATRICK Department of Health and Primary Care University of Oxford Radcliffe Infirmary,
Oxford

OX2 $6 H E$

CRISPIN JENKINSON Nuffield College,

Oxford

1 Bardsley MJ, Venables CW, Watson J, Goodfellow J, Wright PD. Evidence for validity of a health status measure in assessing short term outcomes of cholecystectomy. Quality in Health Care 1992;1:10-14.

2 Patrick D, Peach H. Disablement in the community. Oxford: Oxford University Press,
1989 .

\section{Improving management of asthma}

I wish to take issue with Bucknall and colleagues in their audit of asthma management. ${ }^{1}$ I suggest that what they showed in their article is a change in care but not necessarily an improvement. Their paper discusses changes in process of management, but this has not been linked to an associated improvement in outcome. I think, therefore, that they are unable to conclude that progress through the audit cycle has been made with positive benefit - this statement cannot be made until improvement in outcome is linked with the change in asthma management.

M A WAITE Queen Elizabeth Medical Centre, Queen Elizabeth Hospital, Birmingham B15 $2 T H$

1 Bucknall CE, Robertson C, Moran F, Stevenson RD. Improving management of asthma: closing the loop or progressing along the audit spiral? Quality in Health Care 1992;1:15-20.
AUTHORS' REPLY - Dr Waite addresses an important issue, one for which we do not have the full answer but which is going to be raised regularly as we learn more about audit and as we attempt to measure outcome. Our recent paper ${ }^{1}$ built on previous work ${ }^{2}{ }^{3}$ in which we showed that the management of asthma was suboptimal in a proportion of patients with asthma. Medical management did not conform to accepted good practice, which has subsequently been defined more explicitly. ${ }^{4}$ Furthermore, when the management of patients admitted under the care of a general medical team, including a respiratory physician, was compared with that of those managed in general medical wards with other specialist interests these differences in management were found to be associated with differences in outcome, although the groups were matched for age, sex, severity of index attack, and previous asthma treatment. We have therefore shown previously that there is a good observational basis for the received wisdom that acute asthma should be managed with oral steroids, oxygen, peak flow recordings, and close supervision after discharge.

The present audit could not determine whether the observed improvement in management (now largely in line with accepted good practice) has led to a better outcome as it was retrospective, but we are currently looking at this. Nevertheless, the audit exercise of asking, "Am I doing what I know is 'right?" (accepted good practice) has had a positive benefit as a better standard of practice has now been achieved.

How improving standards of practice will relate to outcome, however it is defined and measured, is as yet largely virgin territory as the medical input is probably only one factor, along with psychological and social factors, which will influence this. ${ }^{5}$ That is why we need to look at outcomes and learn a great deal more about these relations.

CHRISTINE E BUCKNALI
Greater Glasgow Health Board
Glasgow G4 ORA

1 Bucknall CE, Robertson C, Moran F, Stevenson RD. Improving management of asthma: closing the loop or progressing along the audit spiral? Quality in Health Care 1992;1:15-20.

2 Bucknall CE, Robertson C, Moran F, Stevenson RD. Differences in hospital asthma management. Lancet 1988;i:748-50.

3 Bucknall CE, Robertson C, Moran F, Stevenson RD. Management of asthma in hospital: a prospective audit. BMJ 1988;296:1637-9.

4 British Thoracic Society. Guidelines for management of asthma in adults. II. Acute management of asthma in adults. II. Acut
severe asthma. BMF 1990;301:797-800.

5 Jones PW. Quality of life measurement for patients with diseases of the airways. Thorax patients with disease

\section{British eclampsia survey 1992}

The British eclampsia survey is a descriptive epidemiological study of all cases of eclampsia in the United Kingdom during 1992.

The incidence and case mortality from eclampsia in Britain are not known.
However, eclampsia and pre-eclampsia remain major causes of maternal mortality in the United Kingdom and throughout the rest of the world.

Eclampsia contributes significantly to maternal mortality but it is now relatively rare in the United Kingdom and is encountered by only the busiest UK specialists about once every two years, too infrequently to allow the development of the skills or insights that come with frequent experience. The British Eclampsia Survey Team (BEST) will aggregate the currently scattered experience of specialists to create a corporate body of information on eclampsia which is available to all.

The team will review every case of eclampsia occurring in the United Kingdom during 1992. Notifications of cases of eclampsia are being systematically collected from all obstetric consultants and from a liaison midwife in each obstetric hospital in the United Kingdom. However, the team is also keen to receive notifications from anyone who has been involved in any aspect of the care of women with eclampsia or unexplained seizures in pregnancy during 1992. Maternal health, antenatal care, the features and management of eclampsia, and maternal and fetal outcomes are being analysed from a detailed hospital case note review and from a questionnaire to general practitioners. The incidence of eclampsia and the maternal and perinatal case fatality rates associated with eclampsia are being measured; maternal and perinatal morbidity are being recorded, and specific hypotheses concerning the dangers and preventability of eclampsia are being tested.

The survey is being carried out in association with the new medical audit unit of the Royal College of Obstetricians and Gynaecologists. During the survey the foundations for a continuing national register for auditing eclampsia will be established.

Notification forms and further information about the study can be obtained from BEST, Nuffield Department of Obstetrics and Gynaecology, FREEPOST, John Radcliffe Hospital, Headington, Oxford OX3 9BR (0865 221718).

KIRSTY DOUGLAS BEST,
Nuffield Department of Obstetrics and Gynaecology, fohn Radcliffe Maternity Hospital, Headington, Oxford OX3 9DU

\section{Audit spiral}

The terms cycle and loop have been consistently applied to descriptions of the audit process. Indeed the steps involved that is, evaluation of practice, comparison of practice with an accepted standard, and effecting change to improve practice would follow one another repetitively in any clinical audit process.

That this process is indeed a spiral of repeating cycles has been recognised ${ }^{1}$ even if not widely emphasised and was neatly 